\title{
NUSAP1 Promotes Gastric Cancer Progression Through Regulation of Yap Stability
}

Hui Guo

the First Affiliated Hosptial of Nanchang University

Jianping Zou

the First Affiliated Hospital of Nanchang University

\section{Ling Zhou}

the First Affiliated Hospital of Nanchang University

Yan He

the First Affiliated Hospital of Nanchang University

Miao Feng

the First Affiliated Hospital of Nanchang University

Jun Chen

the First Affiliated Hospital of Nanchang University

Junhe Li

the First Affiliated Hospital of Nanchang University

Jianping Xiong

First Affiliated Hospital of Nanchang University

\section{Ziling Fang}

First Affiliated Hospital of Nanchang University

\section{Xiaojun Xiang ( $\square$ xjxiang_nc@163.com )}

Nanchang University

\section{Research}

Keywords: Gastric cancer, NUSAP1, YAP protein, stability, progression

Posted Date: June 9th, 2020

DOl: https://doi.org/10.21203/rs.3.rs-33883/v1

License: (c) (i) This work is licensed under a Creative Commons Attribution 4.0 International License. Read Full License 


\section{Abstract}

Background:Nucleolar and spindle associated protein (NUSAP1) is involved in tumor initiation, progression and metastasis. However, there are limited studies regarding the role of NUSAP1 in gastric cancer (GC).

Methods: The expression profile and clinical significance of NUSAP1 in GC were analysed in online database using GEPIA, Oncomine and KM plotter, which was further confirmed in clinical specimens. The functional role of NUSAP1 were detected utilizing in vitro and in vivo assays. Western blotting, qRT-PCR, the cycloheximide-chase, immunofluorescence staining and Co-immunoprecipitaion (Co-IP) assays were performed to explore the possible molecular mechanism by which NUSAP1 stabilizes YAP protein.

Results:In this study, we found that the expression of NUSAP1 was upregulated in GC tissues and correlates closely with progression and prognosis. Additionally, abnormal NUSAP1 expression promoted malignant behaviors of GC cells in vitro and in a xenograft model. Mechanistically, we discovered that NUSAP1 physically interacts with YAP and furthermore stabilizes YAP protein expression, which induces the transcription of Hippo pathway downstream target genes. Furthermore, the effects of NUSAP1 on GC cell growth, migration and invasion were mainly mediated by YAP.

Conclusions:Our data demonstrates that the novel NUSAP1-YAP axis exerts an critical role in GC tumorigenesis and progression, and therefore could provide a novel therapeutic target for GC treatment.

\section{Background}

Gastric cancer (GC) is one of the most lethal malignancies worldwide and has a particularly high mortality rate in East Asian countries, especially in China and Japan[1]. Despite great progress in surgical and comprehensive therapies, improvements in the clinical outcomes of patients with $\mathrm{GC}$ remain limited[2]. Therefore, it is of utmost importance to explore the molecular mechanism underlying GC tumorigenesis and progression and to identify new therapeutic targets for patients with GC.

Numerous studies have pointed to the pivotal role of Hippo pathway in tissue growth and organ size by a delicate balance between cell proliferation and cell death[3]. The core Hippo pathway consists of a kinase cascade: the upstream kinase MST1/2 phosphorylates and activates the downstream kinase LATS1/2, leading to phosphorylation and inactivation of the transcriptional coactivator YAP[4-6]. Then the phosphorylated YAP translocates to the nucleus and associates with transcription factors, such as the TEA domain (TEAD) family, RUNX and SMADs[7-9], consequently favoring an accelerated rate of cell growth, invasiveness and survival. Upregulation of YAP expression and its nuclear translocation have been frequently detected in several human cancers, including breast cancer, hepatocellular carcinoma and GC[10-12]. Although many studies have outlined that YAP overexpression contributes greatly to GC tumorigenesis, the pathological mechanisms are still poorly understood. 
Nucleolar spindle-associated protein 1 (NUSAP1) is a microtubule-associated protein that plays a critical role in various biological functions, including spindle assembly, chromosome segregation, cytokinesis, microtubule crosslinking, bundling and attachment to chromosomes[13-15]. Studies have shown that NUSAP1 is involved in human malignancies, including pancreatic adenocarcinoma, glioblastoma, hepatocellular carcinoma, prostate cancer and etc[16-20]. High expression of NUSAP1 is positively correlated with poor prognosis in lung cancer and cervical carcinoma[21, 22]. Although NUSAP1 is characterized as an oncogenic driver in several cancers, the underlying mechanisms remain elusive. Zhang et al reported that NUSAP1 depletion suppresses cell proliferation, migration and invasion by regulating CDK1 and DLGAP5 expression in invasive breast cancer cells[23]. Furthermore, the signaling pathways responsible for NUSAP1 functions include PI3K/Akt, Wnt/ $\beta$-catenin and Hedgehog[22, 24, 25], which are highly relevant to tumorigenesis. NUSAP1 is also identified to be upregulated in GC[26]. However, the biological functions of NUSAP1 and the underlying mechanisms in GC still needs to be further discovered.

Here, we found that NUSAP1 was upregulated in GC tissues and cell lines compared to normal gastric tissues and cell lines. These data were the basis for the design of several functional assays to identify whether YAP functions as a potential mediator of the oncogenic activity of NUSAP1 in GC.

\section{Methods}

\section{Ethics statement and clinical tissue samples}

Our study was approved by the Independent Ethical Committee of the First Affiliated Hospital of Nanchang University and complies with the Declaration of Helsinki. Written informed consent was received from all patients. Eight primary GC tissues and their corresponding normal gastric tissues were obtained from the Department of Surgery at the First Affiliated Hospital of Nanchang University. Upon resection, the fresh tissue samples were immediately frozen in liquid nitrogen and stored at $-80^{\circ} \mathrm{C}$ refrigerator. The clinicopathological characteristics of GC patients are summarized in Additional file 1: Table S1. A total of 161 paraffin-embedded gastric cancer samples were included in this study. All GC patients were treatment-naïve before surgery. The clinicopathological features of the GC patients were confirmed by two experienced pathologists at the First Affiliated Hospital of Nanchang University between 2012 and 2016. The clinical and pathological grade was conducted according to the eighth edition of the classification system of the American Joint Committee on Cancer (AJCC).

\section{Cell Lines And Cell Culture}

The human GC cell lines AGS, BGC823, MGC803, HGC-27, SGC7901 and MKN45 and the immortalized gastric epithelial cell line GES-1 were purchased from the Shanghai Institute of Cell Biology, China Academy of Sciences. Cells were cultured in Dulbecco's modified Eagle's medium (DMEM, HyClone, 
Logan, UT, USA) with $10 \%-15 \%$ fetal bovine serum (FBS; HyClone, USA) at $37^{\circ} \mathrm{C}$ in an atmosphere containing $5 \% \mathrm{CO}_{2}$. Cells were harvested at the indicated times posttransfection for future experiments.

\section{Vectors, Lentiviral Infection And Transfection}

Flag-NUSAP1 plasmid was generated by subcloning the PCR-amplified human NUSAP1 coding sequence into the $2 \times$ pcDNA3.1 vector at the Nhel and Hindlll sites. NUSAP1-targeting shRNAs and YAP-targeting siRNA oligonucleotides were designed and synthesized by GenePharma. The sequences of shRNAs and siRNAs used in our study were provided in Additional file 2: Table S2. Cells were seeded on the plate the day before transfection, and transfected with indicated plasmids, shRNAs and siRNAs using TurboFect transfection reagent (Thermo Scientific, R0532, USA). Lentivirus production and infection were conducted as described previously[27]. Stable GC cell lines transfected with scramble shRNA or NUSAP1 shRNAs were selected for two weeks and incubated with $2 \mu \mathrm{g} / \mathrm{mL}$ puromycin upon infection.

\section{Western Blotting Analysis}

Western blotting analysis was conducted using NUSAP1 (1:1000; \#12024-1-AP; Proteintech, Rosemont, IL, USA), YAP (1:1500; \#14074; Cell Signaling Technology, Danvers, USA), LATS1 (1:1500; \#3477; Cell Signaling Technology, Danvers, USA), LATS2 (1:2000; \#5888; Cell Signaling Technology, Danvers, USA), CTGF (1:2000; \#86641; Cell Signaling Technology, Danvers, USA), CYR61 (1:2000; \#14479; Cell Signaling Technology, Danvers, USA), anti-HA (1:2500; \#ab9110; Abcam, Cambridge, USA), anti-Flag (1:2500; \#A2220; Sigma-Aldrich, USA), $\beta$-actin (1:3000; \#AF7018; Affinity, Jiangsu, China) and GAPDH (1:3000; \#A2220; Affinity, Jiangsu, China). Human GC samples originally obtained from the First Affiliated Hospital of Nanchang University were ground and lysed in lysis buffer before western blotting analysis. The western blotting experiments were performed as previously described[28]. GAPDH or $\beta$-Actin was used as an internal control, and all the protein bands were analyzed using ImageJ software.

\section{Immunohistochemistry}

Immunohistochemistry was performed in 161 clinical gastric cancer samples as reported previously[29]. The degree of immunostaining was assessed and scored by two pathologists in a blinded manner. The protein expression of NUSAP1 in gastric cancer specimens by determining the SI (the product of the staining intensity score and the proportion of positive cells), with possible scores of $0,1,2,3,4,6,8,9$, and 12. Samples with a score index $\geq 6$ were considered to have high NUSAP1 expression, and those with a score index $<6$ were considered as low NUSAP1 expression.

\section{Rna Extraction And Quantitative Real-time Pcr}


Total RNA was extracted from cells or xenograft tissues using TRIzol (Invitrogen, Carlsbad, CA, USA) according to the manufacturer's protocol as previously described[30]. Total RNA (0.5 or $1.0 \mu \mathrm{g})$ was used as a template for reverse transcription using poly-(T)20 primers and M-MLV reverse transcriptase (Promega, Madison, USA). Quantitative RT-PCR (qRT-PCR) was performed using SYBR Green Mix following the manufacturer's protocol (BioRad, Hercules, USA). The $2^{-\Delta \Delta C t}$ method was utilized to assess the relative mRNA expression of genes among groups. The primers sequences used are listed in Additional file 3: Table S3.

\section{Cell Counting Kit-8 (cck-8) Assay}

To assess cell growth ability, the CCK-8 assay (Beyotime, China) was utilized following the manufacturer's instructions as previously described ${ }^{40}$. After transfection for $24 \mathrm{~h}$, cells were inoculated in 96-well plates. Cell viability was measured by adding $10 \mu \mathrm{L}$ CCK-8 reagent and incubated for $1 \mathrm{~h}$, then the optical density was measured at the absorbance of samples at $450 \mathrm{~nm}$ in a microplate reader (SpectraMax M5e, USA) for 5 days. The data derived from triplicate samples are shown as the mean \pm standard error of the mean (SEM).

\section{Colony formation assay.}

The colony formation assay was performed as previously described[31]. The indicated transfected HGC27 and BGC823 cells were trypsinized and plated at equal numbers of cells into 6-well plates. Media were changed every 3-4 days until the colonies were visible. Colonies were fixed with $4 \%$ PFA (paraformaldehyde), and stained with $10 \%$ crystal violet at room temperature for 30 min. ImageJ software (Rawak Software, Stuttgart, Germany) was used for quantification of the colonies. These experiments were conducted more than three times.

\section{Wound Healing Assay}

Indicated HGC-27 and BGC823 cells were plated into 6-well plates at a concentration of $4.6 \times 10^{5}$ per well and serum-starved for $24 \mathrm{~h}$ until completely confluent on the second day. A sterile $200 \mu \mathrm{L}$ pipette tip was used to draw straight lines to form a wound. The cells were carefully washed with phosphate-buffered saline (PBS) and cultured in serum-free medium. Images were taken at $0 \mathrm{~h}, 24 \mathrm{~h}$ or $36 \mathrm{~h}$ after scratching to evaluate wound closure. Each experiment was carried out for at least three times.

\section{Transwell Assay}

The transwell chambers were prepared with Matrigel gel, indicated HGC-27 or BGC823 cells were plated into the upper chambers as described previously[32]. After $72 \mathrm{~h}$ of incubation, cells passing through the 
chamber membranes were fixed with $4 \%$ PFA and stained with $10 \%$ crystal violet. These experiments were conducted using three biological replicates.

\section{Immunofluorescence Staining}

The indicated BGC823 cells were fixed in 4\% PFA for 15 min and then treated with $0.5 \%$ Triton X-100 for $10 \mathrm{~min}$. Non-specific bindings were blocked with $5 \%$ bovine serum albumin (BSA) for $30 \mathrm{~min}$. The cells were incubated with the anti-Flag or anti-GFP antibodies at $4{ }^{\circ} \mathrm{C}$ overnight and incubated with the corresponding secondary antibody for $20 \mathrm{~min}$. The 4'-6-diamidino-2-phenylindole (DAPI) was used to stain the nuclei for $30 \mathrm{~min}$. The cellular localization of NUSAP1 or YAP was detected using a confocal microscope (Nikon, ECLIPSE Ti2).

\section{Co-Immunoprecipitation.}

The Co-immunoprecipitation (Co-IP) assay was conducted utilizing indicated antibodies according to the figure legends as previously described ${ }^{40}$. Briefly, $1000 \mu \mathrm{g}$ of total protein was incubated with anti-Flag beads (\#M185-11 MBL, Tokyo, Japan) at $4{ }^{\circ} \mathrm{C}$ for $4 \mathrm{~h}$. The beads were washed with lysis buffer for at least three times. Bound proteins were detected by Western blotting analysis with indicated antibodies described in the figure legends.

\section{Animal Models}

Six to seven-week-old female nude mice were purchased from the SLACCAS Experiment Animal Company (Shanghai, China). $5.6 \times 10^{6}$ indicated BGC823 cells were subcutaneously inoculated into the left axilla of each mouse. Tumor growth was monitored every 3 days with electronic digital calipers (Thermo Scientific) in two dimensions. Tumor volume was measured with the formula: tumor volume $\left(\mathrm{mm}^{3}\right)=$ (length $\times$ width $\left.^{2}\right) / 2$. After 28 days, the mice were sacrificed by euthanasia, and xenograft tumors were harvested and weighed. Total RNA was extracted from tumors via homogenization in TRIzol buffer and then subjected to qRT-PCR analysis.

\section{Statistical analysis}

The SPSS 20.0 software (Chicago, IL, USA) was utilized to perform the statistical analysis. Student's twotailed t-test or the chi-square test was used to determine the mean difference among groups. Survival curves were plotted using the Kaplan-Meier method and compared by the log-rank test. $P<0.05$ was considered statistically significant. All the data are presented as the mean \pm SEM.

\section{Results}

\section{NUSAP1 is upregulated in GC cell lines and tissues}


We first analyzed the expression of NUSAP1 in normal gastric tissues and gastric cancer tissues using data deposited in the GEPIA database (Gene Expression Profiling Interactive Analysis, http://gepia.cancerpku.cn/). As shown in Fig. 1a, NUSAP1 was found to be upregulated in gastric cancer tissues compared to normal gastric tissues. Moreover, analysis of NUSAP1 expression from data deposited from the Oncomine database also revealed that the mRNA expression of NUSAP1 was upregulated in gastric cancer tissues (Fig. 1b, c). To further confirm these data obtained from public datasets, we next detected the expression of NUSAP1 in 8 paired gastric cancer specimens and their corresponding noncancerous tissues and in six gastric cancer cell lines and one immortal gastric epithelial cell line by western blotting. Western blotting analysis showed that the protein expression of NUSAP1 was frequently much higher in gastric cancer tissues than those in paired normal tissues (Fig. 1d). Moreover, compared with the GES-1 cell line, NUSAP1 was also overexpressed in gastric cancer cell lines (Fig. 1e). Thus, our data indicated that NUSAP1 was upregulated in GC cell lines and tissues.

\section{NUSAP1 overexpression is correlated with disease progression as well as poor prognosis in GC patients}

As the expression of NUSAP1 was upregulated in gastric cancer, we further investigated whether there was a correlation between NUSAP1 expression and survival. We performed survival analysis using data obtained from Kaplan-Meier Plotter databases (http://www.kmplot.com) and found that GC patients with higher NUSAP1 mRNA expression had worse overall survival than patients with lower NUSAP1 expression (Fig. 2a, b). The Affymetrix IDs were valid: 218039_at and 219978_S_at. Moreover, further analysis revealed that NUSAP1 upregulation was closely related to shorter relapse-free survival (RFS, Fig. 2c, Affymetrix ID:218039_at). To further verify the clinical significance of NUSAP1 in GC, we further confirm the association between NUSAP1 expression and the clinicopathological characteristics of GC patients using immunohistochemistry in 161 paraffin-embedded gastric cancer tissues. The immunohistochemistry results revealed that NUSAP1 was upregulated in gastric cancer tissues (90/161, $56 \%$ ), and the staining of NUSAP1 increased markedly with clinical TNM stage (Fig. 2d), indicating that overexpression of NUSAP1 contributes to GC progression. Furthermore, the statistical analysis suggested that the NUSAP1 upregulation was correlated with advanced clinical TNM stage $(p=0.006)$, depth of tumor invasion ( $p=0.021)$ and lymph node metastasis $(p=0.039)$ (illustrated clearly in Table 1$)$. Kaplan-

Meier analysis and log-rank testing revealed that the patients with higher NUSAP1 expression had poorer clinical outcomes (median overall survival, 62.6 months vs. 43 months; $p<0.05$, Fig. $2 e$ ). Taken together, these data show that NUSAP1 upregulation contributes to GC progression and correlates with poor survival. 
Table 1

The correlation between the expression of NUSAP1 and clinicopathological parameters of patients with gastric cancer.

\begin{tabular}{|c|c|c|c|c|}
\hline \multicolumn{5}{|c|}{$\begin{array}{l}\text { cases NUSAP1 expression } \\
\text { Factors (n) High Low P value }\end{array}$} \\
\hline \multicolumn{5}{|l|}{ Age (years) } \\
\hline$₫ 65$ & 84 & 44 & 40 & \multirow[t]{2}{*}{0.347} \\
\hline$\geq 65$ & 77 & 46 & 31 & \\
\hline \multicolumn{5}{|l|}{ Gender } \\
\hline Male & 97 & 53 & 44 & \multirow[t]{2}{*}{$0.69^{-}$} \\
\hline Female & 64 & 37 & 27 & \\
\hline \multicolumn{5}{|l|}{ Tumor Size (cm) } \\
\hline$\nabla 5$ & 68 & 33 & 35 & \multirow[t]{2}{*}{0.107} \\
\hline$\geq 5$ & 93 & 57 & 36 & \\
\hline \multicolumn{5}{|l|}{ Differentiation } \\
\hline Well or Moderately & 80 & 40 & 40 & \multirow[t]{2}{*}{0.134} \\
\hline poor & 81 & 50 & 31 & \\
\hline \multicolumn{5}{|l|}{ TNM stage $^{\mathrm{a}}$} \\
\hline$|-| \mid$ & 69 & 30 & 39 & \multirow[t]{2}{*}{0.006} \\
\hline III-IV & 92 & 60 & 32 & \\
\hline \multicolumn{5}{|l|}{ Depth of invasion ${ }^{a}$} \\
\hline $\mathrm{T}_{1}-\mathrm{T}_{2}$ & 81 & 38 & 43 & \multirow[t]{2}{*}{0.021} \\
\hline $\mathrm{T}_{3}-\mathrm{T}_{4}$ & 80 & 52 & 28 & \\
\hline \multicolumn{5}{|l|}{ Tumor location } \\
\hline Proximal & 73 & 37 & 36 & \multirow[t]{2}{*}{0.225} \\
\hline Distal & 88 & 53 & 35 & \\
\hline \multicolumn{5}{|l|}{ Lauren classification } \\
\hline Intestinal type & 99 & 58 & 41 & 0.386 \\
\hline
\end{tabular}




\begin{tabular}{|c|c|c|c|c|}
\hline \multicolumn{5}{|c|}{$\begin{array}{l}\text { cases NUSAP1 expression } \\
\text { Factors (n) High Low P value }\end{array}$} \\
\hline Diffuse type & 62 & 32 & 30 & \\
\hline \multicolumn{5}{|c|}{ Lymph node metastasis } \\
\hline $\mathrm{N}_{0}$ & 76 & 36 & 40 & 0.039 \\
\hline$N_{X}$ & 85 & 54 & 31 & \\
\hline
\end{tabular}

NUSAP1 is required for the proliferation, migration and invasion of GC cells in vitro.

Then we performed a set of functional experiments to assess the role of NUSAP1 in various cellular processes of GC cells. We first confirmed the efficiency of our shRNAs and NUSAP1 expression constructs (Fig. 3a). Growth curves obtained from the CCK-8 assay revealed that NUSAP1 overexpression augmented cell growth in HGC-27 cells, whereas NUSAP1 knockdown markedly decreased cell growth in BGC823 cells (Fig. 3d). These findings were further confirmed by colony forming assays (Fig. 3b, c). Interestingly, NUSAP1 knockdown also markedly decreased the migration and invasion ability of BGC823 cells, while NUSAP1 overexpression enhanced migration and invasion compared to that in control cells (Fig. $3 e, f, g, h$ ). Taken together, our data indicated that NUSAP1 promotes cell proliferation, migration and invasion of GC cells in vitro.

\section{NUSAP1 is a critical driver of YAP activation.}

Previously, our study has demonstrated that the Hippo-YAP pathway plays a critical role in GC tumorigenesis and progression[33,34], which prompted us to wonder whether there was any relationship between NUSAP1 and Hippo-YAP pathway dysregulation. Western blotting analysis of lysates prepared from NUSAP1-modified GC cells showed that the protein expression of YAP and target genes, CRGF and CYR61, were closely related to NUSAP1 protein levels. The protein expression of YAP and its downstream target genes was reduced in NUSAP1-shRNA cells but increased in HGC-27-NUSAP1 cells (Fig. 4a), without significant effects on LATS1/2 protein expression. To investigate the mechanisms by which NUSAP1 regulates YAP activity, we first examined if NUSAP1 regulates YAP transcriptionally. Based on the qRT-PCR results, the mRNA expression of CYR61, FOXM1, EGFR and AREG correlated with overexpression or knockdown of NUSAP1 in GC cells (Fig. 4b, c), without affecting YAP mRNA expression levels. Since NUSAP1 knockdown affected only the protein, but not the mRNA levels of YAP, we next sought to explore the underlying mechanism using a cycloheximide-chase experiment. As clearly shown in Fig. 4d and Additional file 4: Figure S1, ectopic expression of NUSAP1 markedly prolonged YAP's halflife from $2.3 \mathrm{~h}$ to $5.6 \mathrm{~h}$, as compared to control cells. Moreover, NUSAP1 and YAP were co-localized in the nucleus, as shown by immunofluorescence analysis of BGC823 cells (Fig. 4e). Furthermore, the coimmunoprecipitation assay confirmed exogenously that NUSAP1 is a binding partner of YAP (Fig. 4f). 
Collectively, our data indicate that NUSAP1 is a critical driver of YAP activation by binding and stabilizing its protein expression.

\section{YAP mediates NUSAP1-promoted proliferation and invasion in GC cells.}

To determine the role of YAP in NUSAP1-mediated aggressiveness in GC, siRNA targeting YAP was transfected into NUSAP1-overexpressing cells. Ectopic expression and knockdown efficiency were assessed by western blotting analysis, and YAP target genes CTGF and CYR61 were also evaluated. Knockdown of YAP reduced CTGF and CYR61 protein expression and had no significant effect on NUSAP1 expression (Fig. 5a). In addition, YAP deficiency partially negated the effects of NUSAP1 on the protein levels of YAP and its downstream targets (Fig. 5a). Furthermore, CCK-8, colony formation, wound healing and Transwell invasion assays further indicated that NUSAP1-induced proliferation, migration and invasion were partially reversed by YAP depletion in GC cells (Fig. 5b, c, d, e, f, g, h). Taken together, these findings suggest that YAP could moderately rescue the diminished effects induced by NUSAP1 overexpression and this NUSAP1-YAP axis accelerated the proliferation and invasion abilities of GC cells.

\section{Upregulation of NUSAP1 promotes the aggressiveness of GC cells in vivo}

In order to further confirm the biological functions of NUSAP1, we established a xenograft tumor model by inoculating BGC823 cells that expressed scramble shRNA or NUSAP1 shRNA into NOD/SCID mice and monitored tumor size for 28 days. As illustrated in Fig. 6a, NUSAP1 knockdown significantly slowed the growth of xenograft tumors. In line with the tumor growth curve, NUSAP1 knockdown resulted in a markedly reduction in tumor mass and weight (Fig. 6b, c). In accordance with the cell-based results, the mRNA levels of NUSAP1 and CTGF were significantly decreased upon NUSAP1 knockdown without affecting YAP mRNA expression (Fig. 6d). Collectively, our data indicated that NUSAP1 accelerated tumor cell growth in vivo.

\section{Discussion}

In this study, we report that NUSAP1 functions as a positive regulator of YAP to facilitate GC tumorigenesis and progression. Our data show that NUSAP1 is markedly upregulated in GC cell lines and tissues. Moreover, elevated NUSAP1 is an indicator for disease progression and poor survival of patients with GC. Through knockdown and ectopic expression experiments, we demonstrated that NUSAP1 exerts cancer-promoting functions and that these effects are partially reversed by YAP depletion. With regard to the molecular mechanism, we discovered for the first time that NUSAP1 enhances YAP protein stability by physically interacting with YAP. Therefore, we uncovered a previously unrecognized NUSAP1-YAP signaling axis involved in the progression and tumorigenesis of GC.

NUSAP1 upregulation has been detected in a broad range of human cancers, such as prostate cancer, astrocytoma, lung cancer, and breast cancer[20, 21, 23, 25]. For instance, NUSAP1 is highly overexpressed in colon cancer, and its upregulation predicts poor prognosis[35]. Moreover, NUSAP1 functions as a biomarker of prostate cancer and facilitates cell proliferation and invasion[36]. Furthermore, the 
enhanced expression of NUSAP1 in astrocytoma occurs in tandem with the increase in the WHO grade of the tumor[25]. Recent work revealed that patients with high NUSAP1 expression levels were related to unfavorable clinical characteristics and promoted cell proliferation and invasion in GC[26]. However, the potential mechanism of NUSAP1 in GC progression remains unclear. Here, we demonstrated that NUSAP1 is upregulated in $56 \%$ of GC cases and correlates with TNM stage, depth of invasion and lymph node metastasis, potentially leading to the onset of GC. In addition, our study first proposed that NUSAP1 functions as a prognostic factor for patients with GC. Moreover, we demonstrated that overexpression of NUSAP1 strongly accelerates GC cell proliferation, migration and invasion, which are suppressed by NUSAP1 depletion. These data suggest that NUSAP1 may function as an oncogene in human GC.

There is compelling evidence demonstrating that Hippo-YAP signaling is involved in various malignancies, including GC[37]. Increased YAP expression and nuclear accumulation contribute greatly to GC tumor initiation and progression[38, 39], pointing to the essential role of YAP as a potential oncogene and therapeutic target. The YAP protein expression level is canonically regulated by the LATS1/2 kinase of the Hippo pathway and is critical for tumor initiation, progression and metastasis[40, 41]. In this study, we found that NUSAP1 upregulates the expression of downstream targets of the Hippo pathway, including CYR61, CTGF and FOXM1, in gastric cancer cells. In contrast, knockdown of NUSAP1 markedly decreases the protein expression of YAP and the downstream target genes. The fact that LATS1/2 protein did not change markedly in response to modulation of NUSAP1 expression indicates that the regulation of YAP by NUSAP1 is independent of LATS kinase. More interestingly, neither overexpression nor depletion of NUSAP1 caused significant effects on YAP mRNA levels, suggesting that NUSAP1 regulates YAP function through post-transcriptional or protein degradation levels in GC cells.

Stabilization of the YAP protein expression is one of the mechanisms by which YAP exerts its various functions $[42,43]$. Here, we demonstrated that NUSAP1 prolongs YAP's protein half-life by binding to YAP. Furthermore, we confirmed that NUSAP1 and YAP are co-localized in the nucleus, indicating that NUSAP1 may recruit YAP from the cytoplasm to the nucleus, resulting in activation of the transcription of Hippo pathway downstream target genes. However, we did not acquire any direct evidence to precisely show how NUSAP1 promotes the translocation of YAP to the nucleus. Previous studies have shown that the recruitment of $\beta$-TrCP ubiquitin ligase to the $C$-terminal region of YAP facilitates its ubiquitination and degradation[44]. We suspect that NUSAP1 interacts with the C-terminal region of YAP, preventing it from being ubiquitinated by $\beta$-TrCP ligase, thus leading to YAP stabilization and activation. Therefore, an indepth study needs to be implemented to address these questions. More convincingly, the effects of NUSAP1 on GC progression could be partially reversed by YAP depletion, suggesting that YAP acts as a main downstream factor of NUSAP1 to exert its oncogenic functions in GC cells. Based on these findings, we suppose that the NUSAP1-stabilized YAP axis might be responsible for the accelerated malignant behaviors of GC cells. However, our data reveal that NUSAP1-mediated GC cell proliferation, migration and invasion could not be wholly rescued by YAP depletion, suggesting that YAP is not the sole downstream mediator of NUSAP1 in GC cells. NUSAP1 has been demonstrated to regulate several cancerpromoting genes and pathways, including BRCA1, Wnt/ $\beta$-catenin, mTORC1, Hedgehog, etc $[22,25,26,45]$. 
Therefore, it is possible that NUSAP1 overexpression in human GC cells regulates these various oncogenes and pathways.

\section{Conclusion}

In summary, our study unveils that NUSAP1 functions as another novel and positive regulator of YAP, and increased NUSAP1 expression lead to stabilization of YAP oncoprotein, thus facilitates tumorigenesis and progression of GC (Fig. 7).

\section{Abbreviations}

GC

Gastric cancer; NUSAP1:Nucleolar spindle-associated protein 1; YAP:Yes1 associated transcriptional regulator; LATS1:large tumor suppressor kinase 1; LATS2:large tumor suppressor kinase 2; CTGF:connective tissue growth factor; AREG:amphiregulin; CHX:cycloheximide; CDK1:cyclin dependent kinase 1; CCK-8:cell counting kit-8; qRT-PCR:Quantitative reverse transcriptase polymerase chain reaction.

\section{Declarations}

\section{Acknowledgements}

Our study was funded by the National Natural Science Foundation of China Grant (grants 81660402 and81869545),the Natural Science Foundation of JiangXi Province Grant (grants $20192 B A B 215040$ and 20192BAB205073), the Jiangxi Provincial Outstanding Young Talents projects (grant 20192BCB23020) and Education Department of Jiangxi Province (grant 701238001) and Department of Health Project of Jiangxi Province (grant 20201015).

\section{Funding}

Our study was funded by the National Natural Science Foundation of China Grant (grants 81660402 and 81869545),the Natural Science Foundation of JiangXi Province Grant (grants $20192 B A B 215040$ and 20192BAB205073), the Jiangxi Provincial Outstanding Young Talents projects (grant 20192BCB23020) and Education Department of Jiangxi Province (grant 701238001) and Department of Health Project of Jiangxi Province (grant 20201015).

\section{Availability of data and materials}

All the data generated or analysed in our study were included in our published article and the additional files.

\section{Authors' contributions}


GH and ZJ conducted the laboratory experiments; to acquisition of data and technical support.ZL and HY contributed to analysis and technical support. ZM and LJcontributed to collection and analysis of clinical samples. FM and $\mathrm{CJ}$ revised the manuscript forimportant intellectual content. $\mathrm{XJ}$ and $\mathrm{FZ}$ contributed to study conceptand design, analysis and interpretation of data and drafting of themanuscript. XX contributed to analysis and interpretation of data and drafting of themanuscript.All authors read and approved the final manuscript.

\section{Competing interests}

All the authors declare that they have no conflicts of interest.

\section{Consent for publication}

Not applicable.

\section{Ethicsapproval andconsent to participate}

The written informed consent was given from the patients included in our study. And this study was approved by the Independent Ethics Committee of the FirstAffiliated Hospital of Nanchang University.

\section{References}

1. Torre LA, Bray F, Siegel RL, Ferlay J, Lortet-Tieulent J, Jemal A. Global cancer statistics, 2012. CA Cancer J Clin. 2015;65(2):87-108.

2. Wadhwa R, Song S, Lee JS, Yao Y, Wei Q, Ajani JA. Gastric cancer-molecular and clinical dimensions. Nat Rev Clin Oncol. 2013;10(11):643-55.

3. Yu FX, Zhao B, Guan KL. Hippo Pathway in Organ Size Control, Tissue Homeostasis, and Cancer. Cell. 2015;163(4):811-28.

4. Yu FX, Guan KL. The Hippo pathway: regulators and regulations. Genes Dev. 2013;27(4):355-71.

5. Moroishi T, Hayashi T, Pan WW, Fujita Y, Holt MV, Qin J, et al. The Hippo Pathway Kinases LATS1/2 Suppress Cancer Immunity. Cell. 2016;167(6):1525-39.e17.

6. Zanconato F, Cordenonsi M, Piccolo S. YAP/TAZ at the Roots of Cancer. Cancer Cell. 2016;29(6):783-803.

7. Hill CS. Transcriptional Control by the SMADs. Cold Spring Harb Perspect Biol. 2016; 8(10).

8. Wu S, Liu Y, Zheng Y, Dong J, Pan D. The TEAD/TEF family protein Scalloped mediates transcriptional output of the Hippo growth-regulatory pathway. Dev Cell. 2008;14(3):388-98.

9. Passaniti A, Brusgard JL, Qiao Y, Sudol M, Finch-Edmondson M. Roles of RUNX in Hippo Pathway Signaling. Adv Exp Med Biol. 2017;962:435-48.

10. Wu L, Yang X. Targeting the Hippo Pathway for Breast Cancer Therapy. 2018; 10(11). 
11. Moon H, Cho K, Shin S, Kim DY, Han KH, Ro SW. High Risk of Hepatocellular Carcinoma Development in Fibrotic Liver: Role of the Hippo-YAP/TAZ Signaling Pathway. Int J Mol Sci. 2019; 20(3).

12. Choi W, Kim J, Park J, Lee DH, Hwang D, Kim JH, et al. YAP/TAZ Initiates Gastric Tumorigenesis via Upregulation of MYC. Cancer Res. 2018;78(12):3306-20.

13. Raemaekers T, Ribbeck K, Beaudouin J, Annaert W, Van Camp M, Stockmans I, et al. NuSAP, a novel microtubule-associated protein involved in mitotic spindle organization. J Cell Biol. 2003;162(6):1017-29.

14. Ribbeck K, Raemaekers T, Carmeliet G, Mattaj IW. A role for NuSAP in linking microtubules to mitotic chromosomes. Curr Biol. 2007;17(3):230-6.

15. Vanden Bosch A, Raemaekers T, Denayer S, Torrekens S, Smets N, Moermans K, et al. NuSAP is essential for chromatin-induced spindle formation during early embryogenesis. J Cell Sci. 2010;123(Pt 19):3244-55.

16. Kokkinakis DM, Liu X, Neuner RD. Modulation of cell cycle and gene expression in pancreatic tumor cell lines by methionine deprivation (methionine stress): implications to the therapy of pancreatic adenocarcinoma. Mol Cancer Ther. 2005;4(9):1338-48.

17. Qian Z, Li Y, Ma J, Xue Y, Xi Y, Hong L, et al. Prognostic value of NUSAP1 in progression and expansion of glioblastoma multiforme. 2018; 140(2):199-208.

18. Zhu T, Xie P, Gao YF, Huang MS, Li X, Zhang W, et al. Nucleolar and spindle-associated protein 1 is a tumor grade correlated prognosis marker for glioma patients. 2018; 24(3):178-86.

19. Roy S, Hooiveld GJ, Seehawer M, Caruso S, Heinzmann F, Schneider AT, et al. microRNA 193a-5p Regulates Levels of Nucleolar- and Spindle-Associated Protein 1 to Suppress Hepatocarcinogenesis. Gastroenterology. 2018;155(6):1951-66.e26.

20. Gulzar ZG, McKenney JK, Brooks JD. Increased expression of NuSAP in recurrent prostate cancer is mediated by E2F1. Oncogene. 2013;32(1):70-7.

21. Yu Z, Li XM, Huai M, Cao SS, Han HY, Liu HT. [Expression of NUSAP1 and its relationship with prognosis in non-small cell lung cancer]. Zhonghua Zhong Liu Za Zhi. 2019;41(7):522-26.

22. Li H, Zhang W, Yan M, Qiu J, Chen J, Sun X, et al. Nucleolar and spindle associated protein 1 promotes metastasis of cervical carcinoma cells by activating Wnt/ $\beta$-catenin signaling. J Exp Clin Cancer Res. 2019;38(1):33.

23. Zhang X, Pan Y, Fu H, Zhang J. Nucleolar and Spindle Associated Protein 1 (NUSAP1) Inhibits Cell Proliferation and Enhances Susceptibility to Epirubicin In Invasive Breast Cancer Cells by Regulating Cyclin D Kinase (CDK1) and DLGAP5 Expression. Med Sci Monit. 2018;24:8553-64.

24. Xu Z, Wang Y, Xiong J, Cui F, Wang L, Peng H. NUSAP1 knockdown inhibits cell growth and metastasis of non-small-cell lung cancer through regulating BTG2/PI3K/Akt signaling. 2020; 235(4):3886-93.

25. Wu X, Xu B, Yang C, Wang W, Zhong D, Zhao Z, et al. Nucleolar and spindle associated protein 1 promotes the aggressiveness of astrocytoma by activating the Hedgehog signaling pathway. J Exp Clin Cancer Res. 2017;36(1):127. 
26. Ge Y, Li Q, Lin L, Jiang M, Shi L, Wang B, et al. Downregulation of NUSAP1 suppresses cell proliferation, migration, and invasion via inhibiting $\mathrm{mTORC} 1$ signalling pathway in gastric cancer. 2020; 38(1):28-37.

27. Fang Z, Cao B, Liao JM, Deng J, Plummer KD, Liao P, et al. SPIN1 promotes tumorigenesis by blocking the uL18 (universal large ribosomal subunit protein 18)-MDM2-p53 pathway in human cancer. Elife. 2018; 7.

28. Fang Z, Zhang L, Liao Q, Wang Y, Yu F, Feng M, et al. Regulation of TRIM24 by miR-511 modulates cell proliferation in gastric cancer. J Exp Clin Cancer Res. 2017;36(1):17.

29. Fang Z, Deng J, Zhang L, Xiang X, Yu F, Chen J, et al. TRIM24 promotes the aggression of gastric cancer via the Wnt/beta-catenin signaling pathway. Oncol Lett. 2017;13(3):1797-806.

30. Wang H, Fang ZL, Zhang GH, Ma X. TRIM44, a crucial target of miR-410, functions as a potential oncogene in osteosarcoma. Onco Targets Ther. 2018;11:3637-47.

31. Han X, Fang Z, Wang H, Jiao R, Zhou J, Fang N. CUL4A functions as an oncogene in ovarian cancer and is directly regulated by miR-494. Biochem Biophys Res Commun. 2016;480(4):675-81.

32. Deng J, Lei W, Xiang X, Zhang L, Lei J, Gong Y, et al. Cullin 4A (CUL4A), a direct target of miR-9 and miR-137, promotes gastric cancer proliferation and invasion by regulating the Hippo signaling pathway. Oncotarget. 2016;7(9):10037-50.

33. Liu Z, Huang S, Cao Y, Yao Y, Li J, Chen J, et al. YAP1 inhibits circRNA-000425 expression and thus promotes oncogenic activities of miR-17 and miR-106. Biochem Biophys Res Commun. 2018;503(4):2370-75.

34. Huang S, Zhu L, Cao Y, Li L, Xie Y, Deng J, et al. Significant association of YAP1 and HSPC111 proteins with poor prognosis in Chinese gastric cancer patients. Oncotarget. 2017;8(46):80303-14.

35. Liu Z, Guan C, Lu C, Liu Y, Ni R, Xiao M, et al. High NUSAP1 expression predicts poor prognosis in colon cancer. Pathol Res Pract. 2018;214(7):968-73.

36. Gordon CA, Gulzar ZG, Brooks JD. NUSAP1 expression is upregulated by loss of RB1 in prostate cancer cells. Prostate. 2015;75(5):517-26.

37. Qiao Y, Li T, Zheng S, Wang H. The Hippo pathway as a drug target in gastric cancer. Cancer Lett. 2018;420:14-25.

38. Hu X, Xin Y, Xiao Y, Zhao J. Overexpression of YAP1 is correlated with progression, metastasis and poor prognosis in patients with gastric carcinoma. Pathol Oncol Res. 2014;20(4):805-11.

39. Yan H, Qiu C, Sun W, Gu M, Xiao F, Zou J, et al. Yap regulates gastric cancer survival and migration via SIRT1/Mfn2/mitophagy. Oncol Rep. 2018;39(4):1671-81.

40. Hao Y, Chun A, Cheung K, Rashidi B, Yang X. Tumor suppressor LATS1 is a negative regulator of oncogene YAP. J Biol Chem. 2008;283(9):5496-509.

41. Oka T, Mazack V, Sudol M. Mst2 and Lats kinases regulate apoptotic function of Yes kinaseassociated protein (YAP). J Biol Chem. 2008;283(41):27534-46. 
42. Wang P, Gong Y, Guo T, Li M, Fang L, Yin S, et al. Activation of Aurora A kinase increases YAP stability via blockage of autophagy. Cell Death Dis. 2019;10(6):432.

43. Ji J, Xu R, Zhang X, Han M, Xu Y, Wei Y, et al. Actin like-6A promotes glioma progression through stabilization of transcriptional regulators YAP/TAZ. Cell Death Dis. 2018;9(5):517.

44. Shanzer M, Adler J, Ricardo-Lax I, Reuven N, Shaul Y. The nonreceptor tyrosine kinase c-Src attenuates SCF $(\beta$-TrCP) E3-ligase activity abrogating Taz proteasomal degradation. Proc Natl Acad Sci U S A. 2017;114(7):1678-83.

45. Kotian S, Banerjee T, Lockhart A, Huang K, Catalyurek UV, Parvin JD. NUSAP1 influences the DNA damage response by controlling BRCA1 protein levels. Cancer Biol Ther. 2014;15(5):533-43.

\section{Figures}
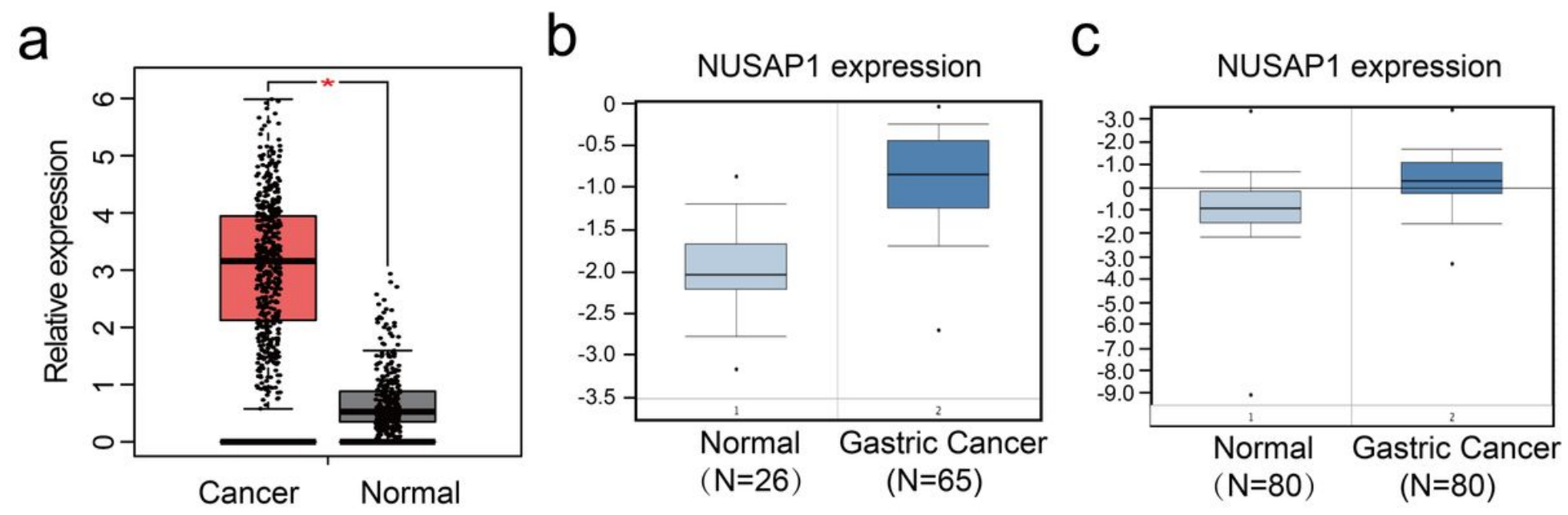

d

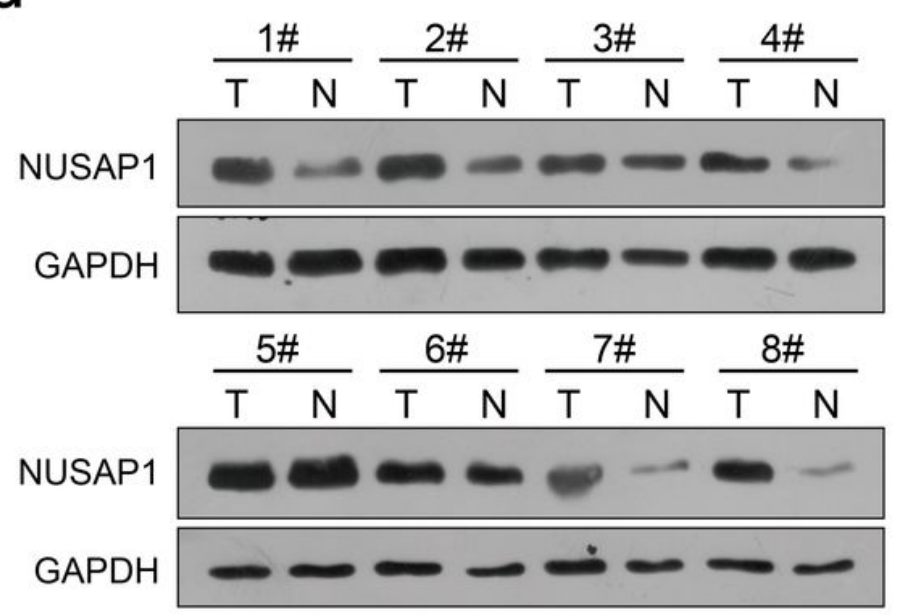

e

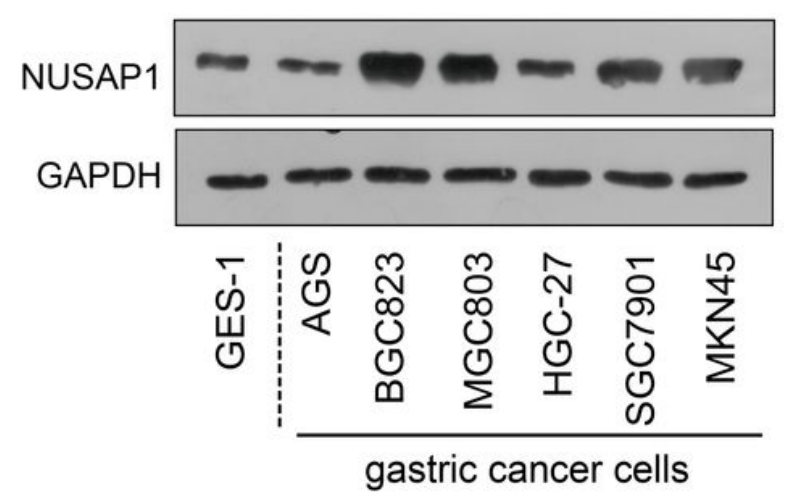

Figure 1

NUSAP1 is upregulated in gastric cancer cell lines and tissues. a Analysis of the relative mRNA expression of NUSAP1 in the GEPIA database (Student's $t$ test, $p<0.05$ ). b, c The expression profile of 
NUSAP1 in gastric cancer and normal tissues was searched in the Oncomine Gene Browser (Student's t test, $p<0.05)$. $d$ Western blotting analysis of NUSAP1 levels in lysates prepared from 8 paired gastric cancer tissues and normal gastric tissues. e Western blotting analysis of NUSAP1 levels in GES-1, AGS, BGC823, MGC803, HGC-27, SGC7901 and MKN45 cell lines. GAPDH was used as a loading control.

a

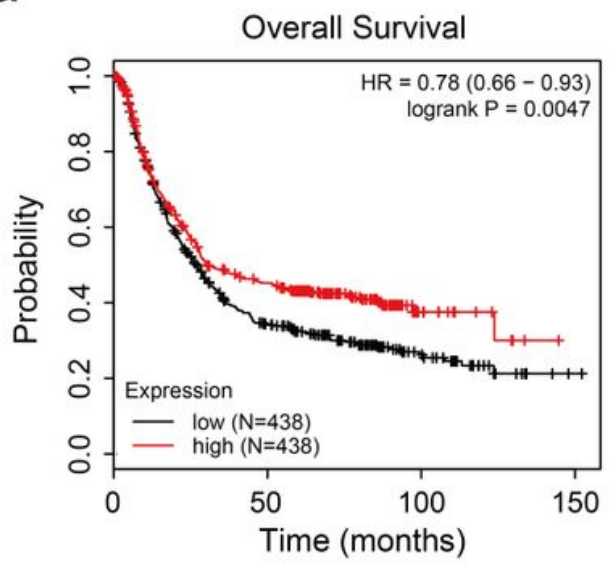

d
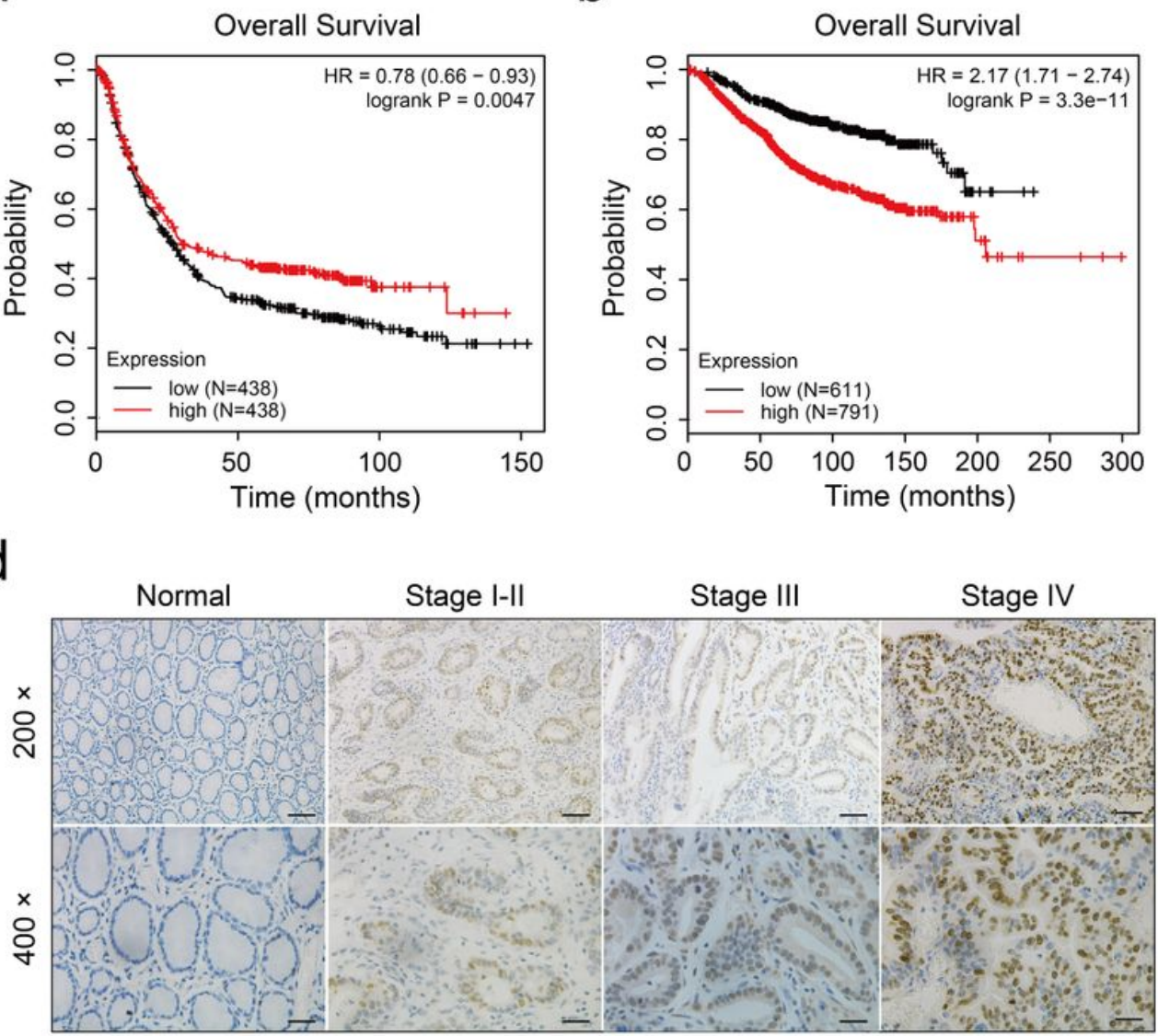

b

e

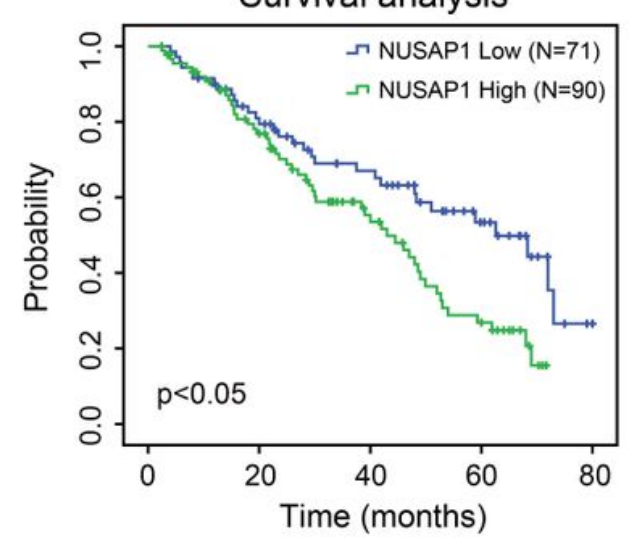

Figure 2

NUSAP1 overexpression is correlated with disease progression as well as poor prognosis in GC patients. $a, b$ The correlation between NUSAP1 expression and overall survival in patients with GC obtained from Kaplan-Meier Plotter databases (log-rank test, $\mathrm{p}<0.01$ ). c The correlation between NUSAP1 expression and relapse-free survival (RFS) in patients with GC obtained from Kaplan-Meier Plotter databases (log-rank test, $\mathrm{p}<0.01)$. d Representative images of IHC staining of NUSAP1 in human gastric cancer tissues and non-neoplastic tissue samples. Scale bars represent $50 \mu \mathrm{M}$ or $25 \mu \mathrm{M}$. e Kaplan-Meier survival analysis performed with survival data of gastric patients with high NUSAP1 expression $(n=90)$ vs. Iow NUSAP1 expression $(n=71)$, Log-rank test, $p=0.012$. 
a

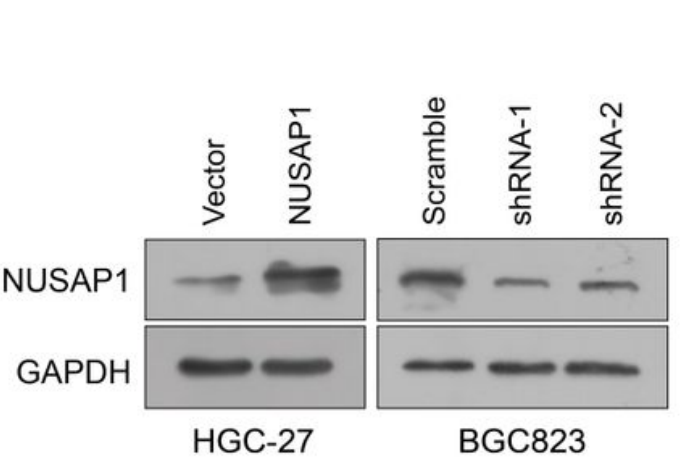

b

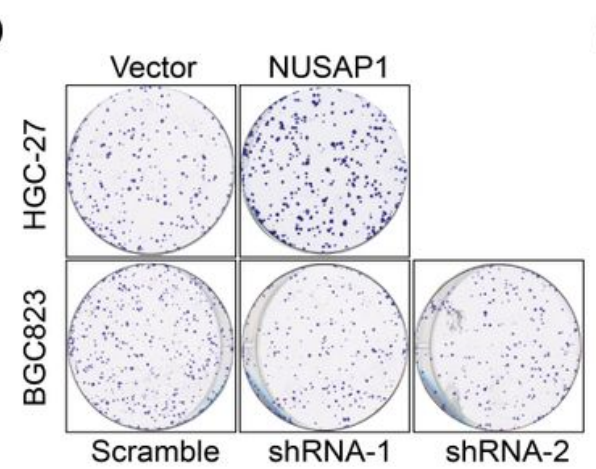

e

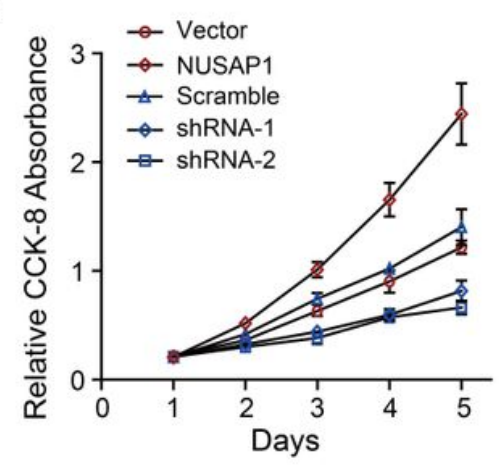

g

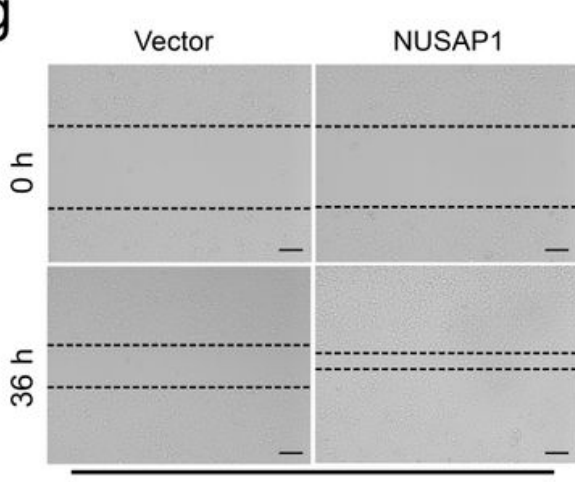

HGC-27

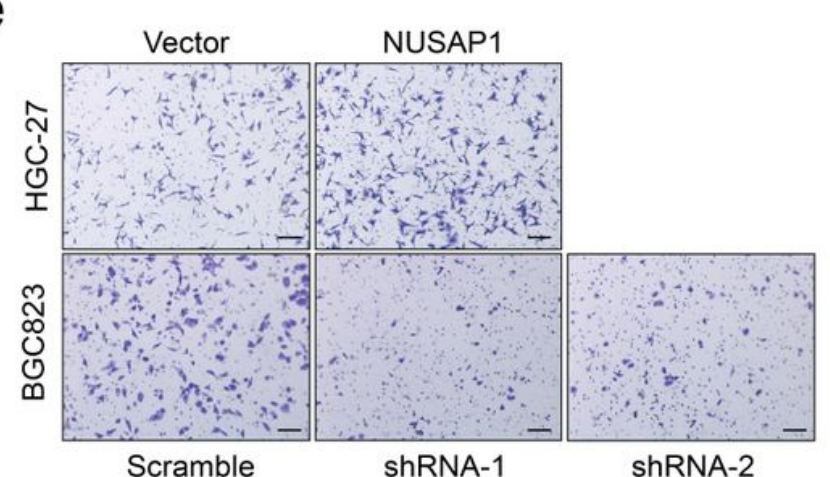

Scramble

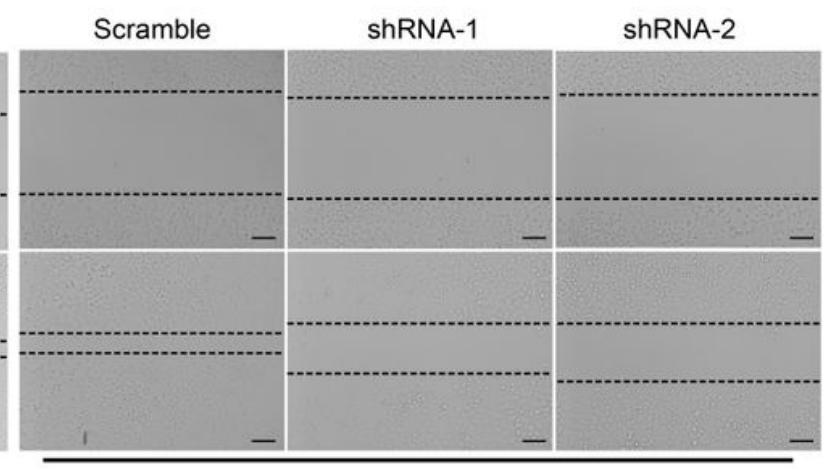

BGC823

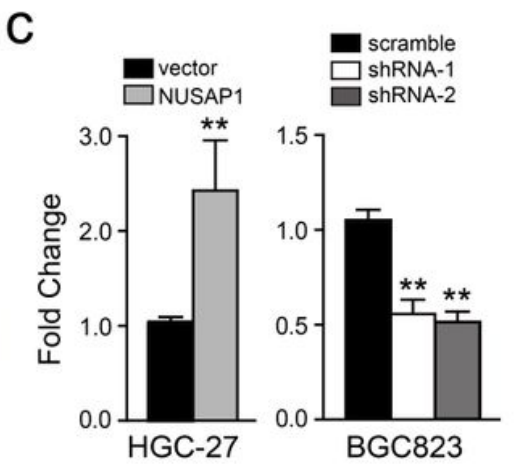

f

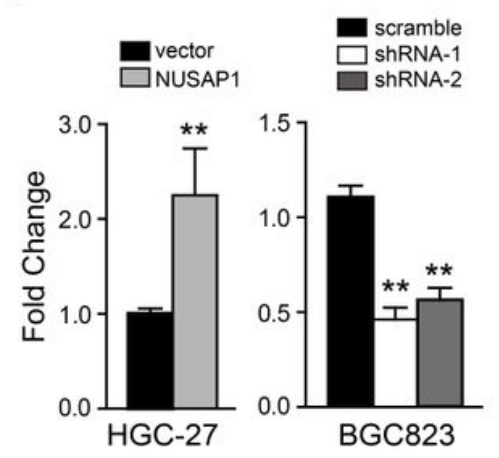

$\mathrm{h}$

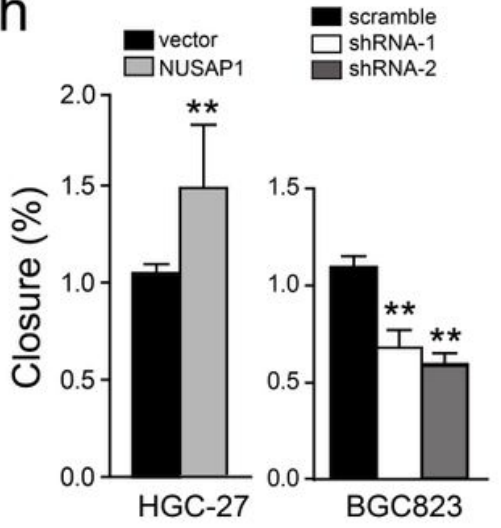

Figure 3

NUSAP1 is required for the proliferation, migration and invasion of GC cells in vitro. a HGC-27 and BGC823 cells were transfected with Flag-NUSAP1 or NUSAP1 shRNAs, and the efficiency was detected by western blotting. b, c Representative images of colony formation assays for modified HGC-27 and BGC823 cells. Cells were fixed and stained, the colonies were counted, and the data are represented in the bar graph. $d$ Cell viability was analyzed by CCK-8 assay. e, $f$ Representative images of fixed and stained modified HGC-27 and BGC823 cells in the Transwell invasion assays (magnification, $\times 200$ ). $\mathrm{g}, \mathrm{h}$ Cell migration ability evaluated by wound healing assays (magnification, $\times 100$ ). Student's $t$ test: ${ }^{*} p<0.05$, ${ }^{*} \mathrm{p}<0.01$. 
a

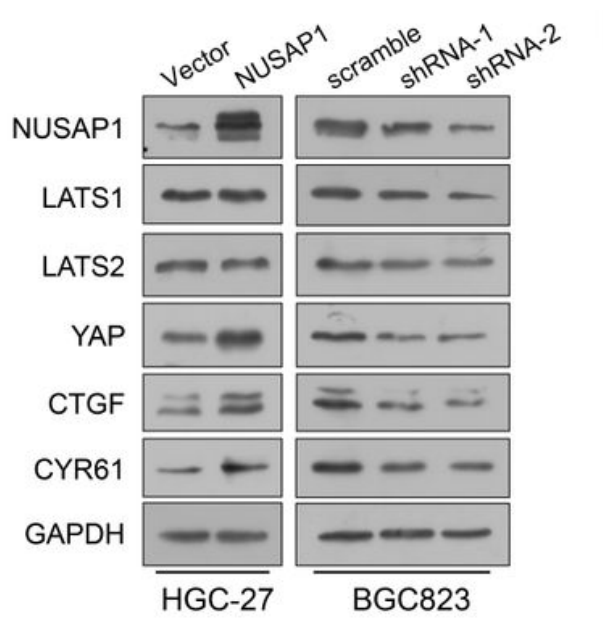

b

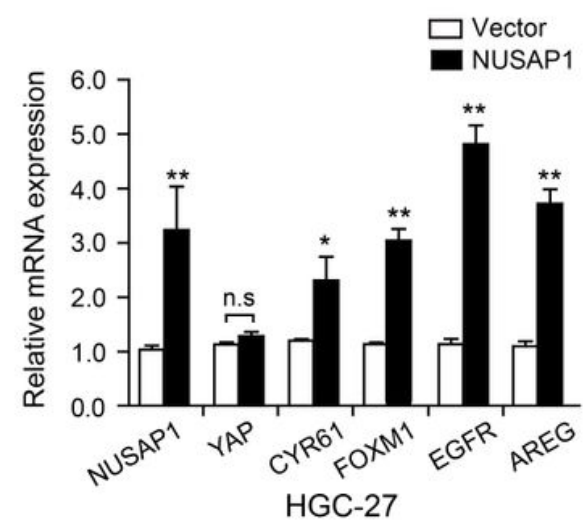

e Flag-NUSAP1

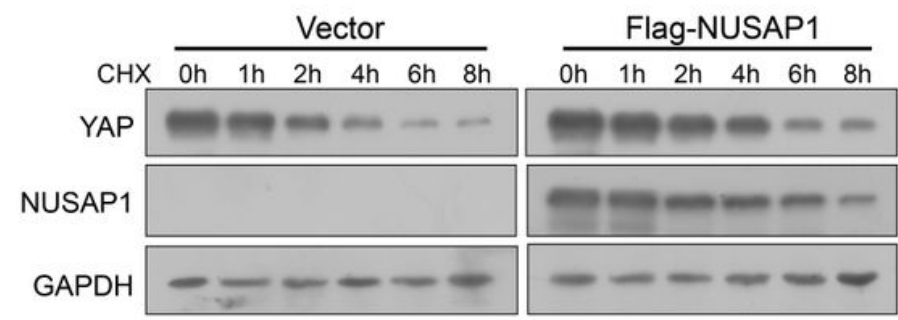

BGC823
C

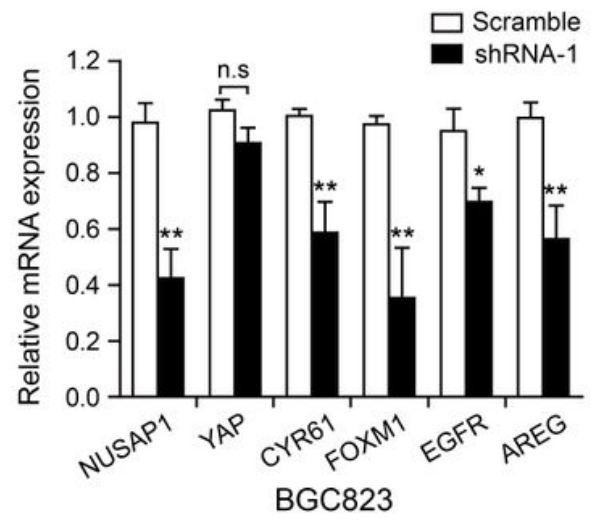

f

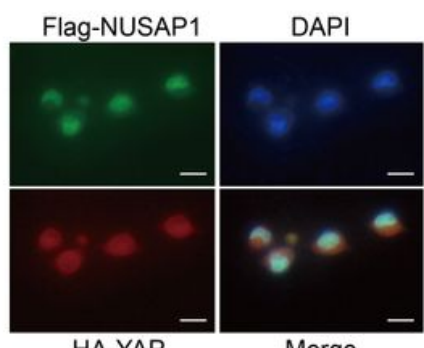

HA-YAP

Merge

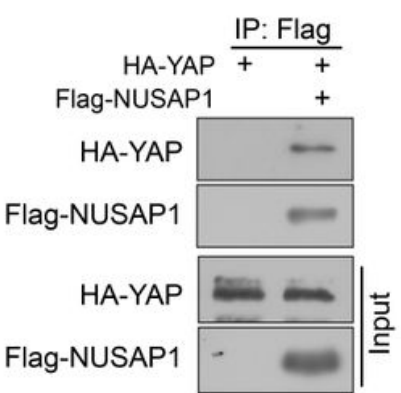

Figure 4

NUSAP1 is a critical driver of YAP activation. a Western blotting analysis to evaluate LATS1/2, YAP, and YAP downstream target genes CTGF and CYR61 in lysates prepared from modified cell lines HGC-27 and BGC823. GAPDH was used as a loading control. b, c qRT-PCR analysis of YAP and its downstream target genes CYR61, FOXM1, EGFR and AREG in modified HGC-27 and BGC823 cells. Relative expression is shown over GAPDH mRNA. d Western blotting analysis of YAP protein in modified BGC823 cells treated with $\mathrm{CHX}(25 \mu \mathrm{g} / \mathrm{mL})$ for the indicated times. The line graph shows YAP levels normalized to GAPDH at the indicated time points. e Immunofluorescence of NUSAP1 and YAP staining in BGC823 cells (magnification, $\times 400$ ). $f$ Western blotting analysis of co-precipitating proteins in IPs performed using antiFlag beads on lysates prepared from BGC823 cells. Student's t test: ${ }^{\star} p<0.05,{ }^{\star *} p<0.01$. 

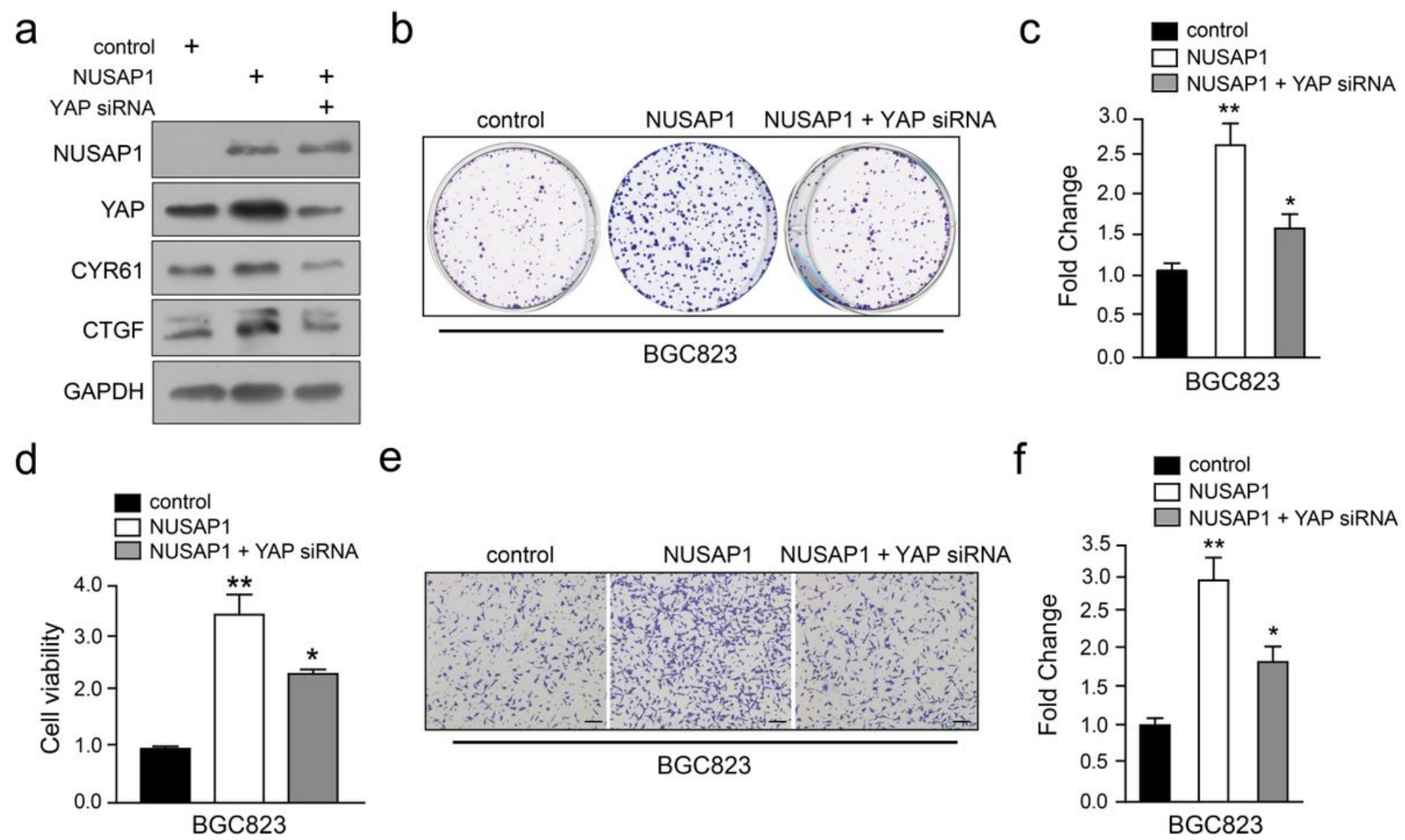

g
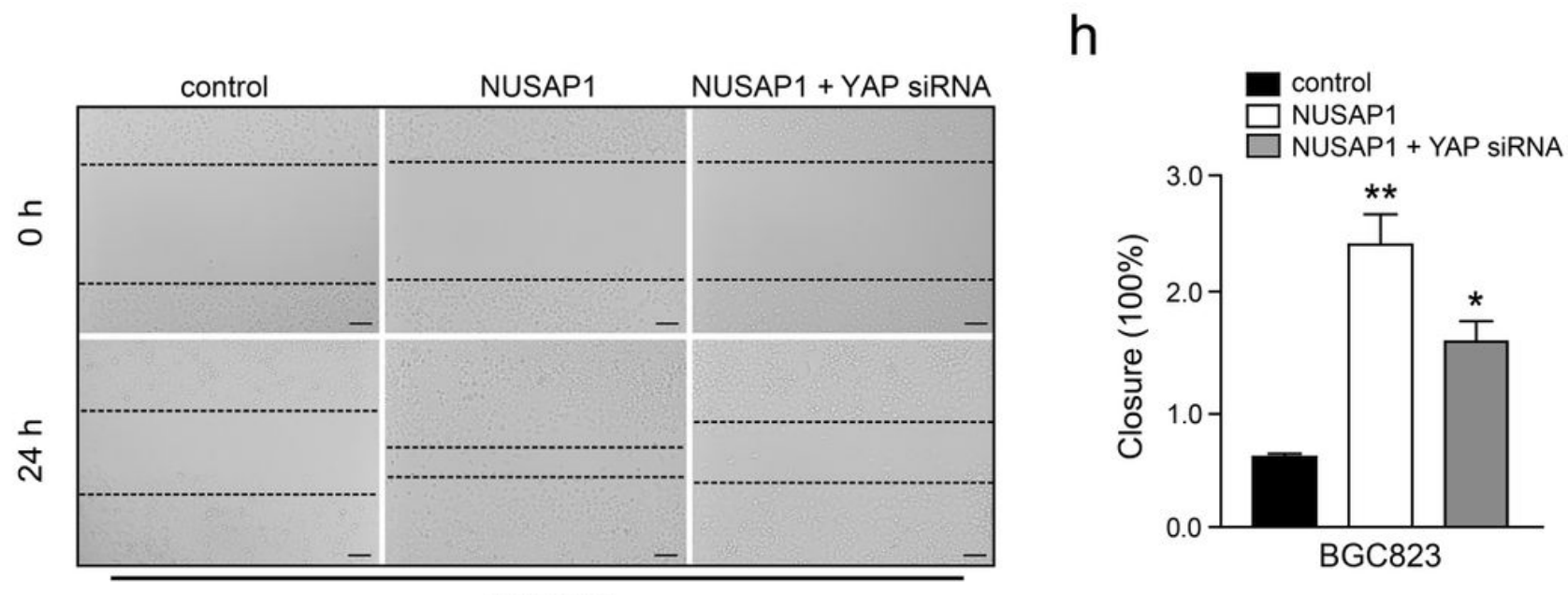

BGC823

Figure 5

YAP mediates NUSAP1-promoted proliferation, migration and invasion in GC cells. a Western blotting analysis of lysates prepared from NUSAP1-overexpressing GC cells with YAP siRNA. GAPDH was used as a loading control. $b$ Colony formation assay performed on NUSAP-overexpressing BGC823 cells with YAP knockdown. c Graphic representation of the colony numbers under the indicated transfection condition. $d$ CCK-8 assay performed on NUSAP-overexpressing BGC823 cells with YAP knockdown. e Representative images of fixed and stained Transwell invasion assays performed on modified BGC823 cells (magnification, $\times 200$ ). $f$ Graphic representation of invaded cell counts from the Transwell assays. $g$, $h$ Cell migration ability evaluated by wound healing assays performed on modified BGC823 cells 
(magnification, $\times 200$ ). One-way analysis of variance (adjusted for Bonferroni correction's test). All data are presented as the mean \pm SEM of triplicate experiments, $n=3, * P<0.05$ and $* * P<0.01$.

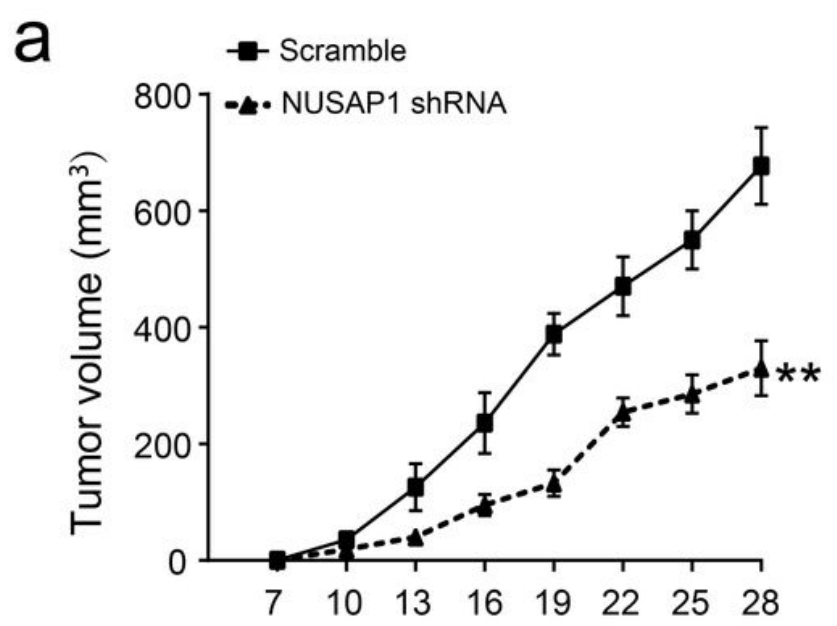

b

Day after inoculation

C

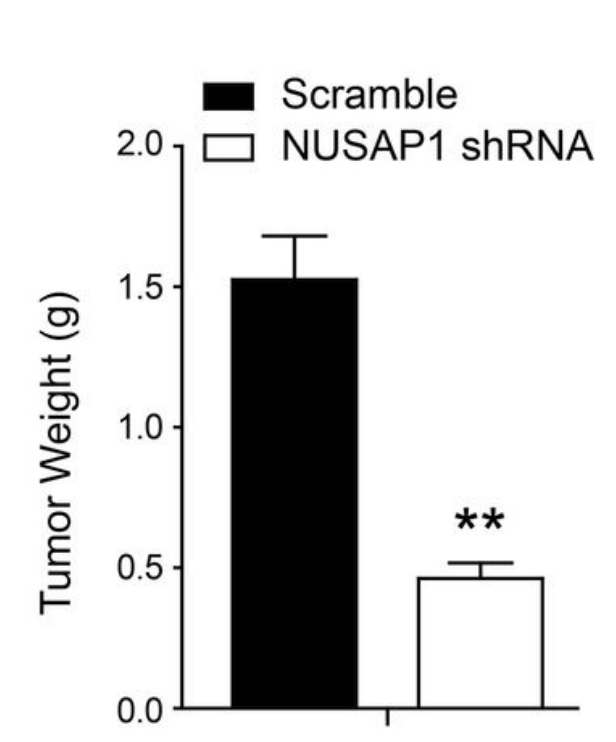

d

NUSAP1 shRNA

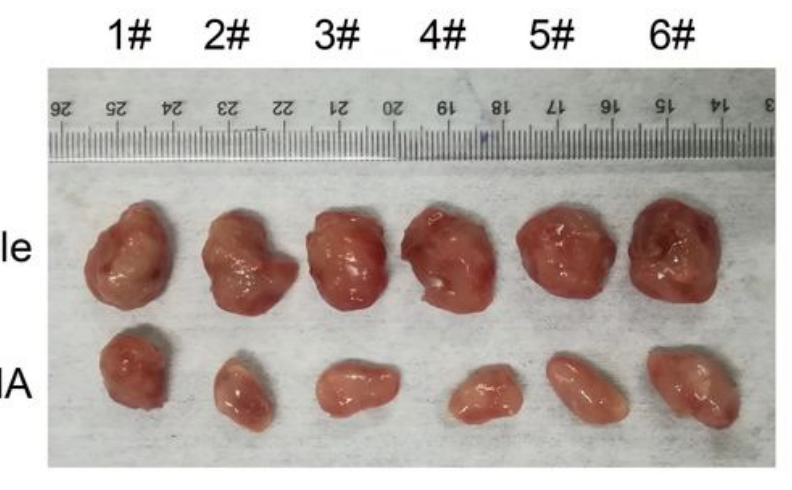

Scramble

\section{Figure 6}

Upregulation of NUSAP1 promotes the aggressiveness of GC cells in vivo. a Growth curves of xenograft tumors derived from BGC823 cells that expressed scramble or NUSAP1 shRNAs. Data are represented as the mean $\pm S E M, n=6$. $b$ The images of xenograft tumors that were harvested at the end of experiment. $c$ Quantification of the average weights of collected tumors from the above experiments. $d$ The mRNA levels of NUSAP1, YAP and CTGF were detected in six tumors by qRT-PCR (mean $\pm S E M, n=6$ ). ${ }^{*} p<0.05$, ** $p<0.01$ by two-tailed t-test. 


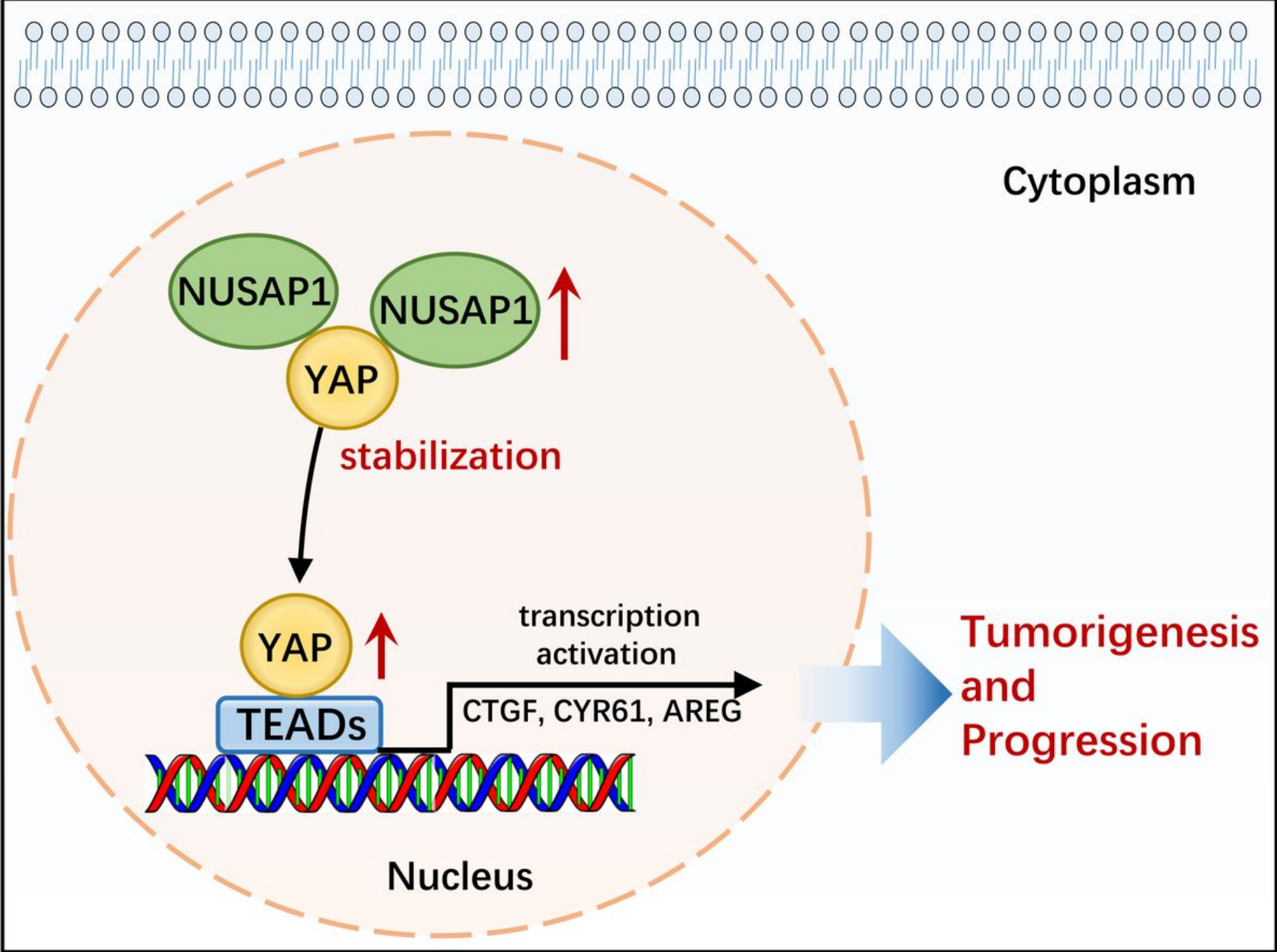

Figure 7

A model for SPIN1 regulation of YAP protein stability in gastric cancer. Upregulated NUSAP1 interacted with and stabilized YAP protein, thus increasing YAP abundance, leading to the activation of Hippo pathway downstream targets, finally facilitated tumorigenesis and progression of GC.

\section{Supplementary Files}

This is a list of supplementary files associated with this preprint. Click to download.

- FigureS1.jpg

- SupplementaryTableS1.docx

- SupplementaryTableS2.docx

- SupplementaryTableS3.docx

- Additionalfiles.docx 